\title{
An analysis of constraint and problems in production and marketing of Nagauri (Paan) methi in Rajasthan State of India
}

\author{
Pawariya V. ${ }^{1}$ 伲, Poonia M. K. ${ }^{2}$, Ram N. ${ }^{3}$, Yadav M. M. ${ }^{4}$, Dagar V. ${ }^{5}$
}

Received: 25.10 .2020

Revised: 27.11 .2020

Accepted: 03.12.2020

\begin{abstract}
The present study was undertaken in the production area majorly Nagaur and in some part of Jodhpur district of Rajasthan to access the problems and constraints faced by farmers in the production and marketing of Nagauri (Paan) methi. A total sample of 150 farmers from 30 villages of two districts were selected for the study. The primary data were collected from the farmers by using pre tested structured schedule. The results from investigation shows that most important problem ranked first (Garret's mean score is 75.60) was faced by farmers are lack of remunerative price of the product, which is $90 \%$ of farmers were facing followed by lack of proper market center (Rank II), monopoly of traders (presence of less competitive firms), higher price spread. Least marketing constraint was payment delay which was faced by 55 per cent farmers ranked XIII. The major production constraints were drying of leaves (Garret's mean score is 73.41) ranked I followed by irrigation and less use of technology. The appropriate policy suggestions are market establishment, government intervention to provide the remunerative price of Nagauri (Paan) methi and technology use.
\end{abstract}

Key Words: Garrett's technique, Marketing constraint, Nagauri (Paan) methi, Price spread, Production constraints

\section{Introduction}

Agriculture is full of risk and uncertainty as the business activities in the profession is reliant on natural conditions. The major problems faced by farmers in the growing of agricultural crops in the Rajasthan state are market facilities, lack of storage facilities, grading, standardization transportation, risk management, price volatility, monopoly of traders, and malpractices in legal acts. Nagauri (Paan) methi is one of the important crops which are prevalently grown in the Nagaur district and some part of Jodhpur district in Rajasthan state. Nagauri (Paan) methi is being grown by more than 3000 farmers in the 4100 hectares area. The majorly grown area is Nimdi, Kuchera, Run, Khajwana of the district. Fenugreek is majorly grown in the state of Rajasthan, Kashmir, Punjab and upper Gangetic plains. Fenugreek has the two

\section{Author's Address}

${ }^{1}$ Department of Agricultural Economics, College of Agriculture, Nagaur, Agriculture University, Jodhpur, Rajasthan-India

${ }^{2}$ Department of Horticulture, College of Agriculture, Nagaur, Agriculture University, Jodhpur,Rajasthan-India

${ }^{3}$ Department of Entomology, College of Agriculture, Nagaur, Agriculture University, Jodhpur,Rajasthan-India

${ }^{4}$ School of Agriculture, Jaipur National University, Jaipur

${ }^{5}$ Department of Economics, Delhi School of Economics, Delhi

University, New Delhi- India

E-mail.: vikashpawariya@gmail.com species i.e. Foenum-granum (common methi) and Foenum-corniculata (Nagauri/Paan methi). This crop is being grown in Rabi season in Rajasthan.

The moderate rate of rain can be bear by this crop. In heavy rain this crop cannot withstand and the problem of seed setting and drainage occur. Pusa Paan, Pant Ragini and Pusa early bunching are major released varieties of this crop. So lesser number of variety advancement in the Nagauri (Paan) methi. It matures in the 170-180 days and its average yield is $70-80$ Quintal/hectare and average seed yield is 12 Quintal/hectare. Its green leaves are very perishable in nature and need to get into markete very soon. Once, the leaves well dried then it will remain with the economic value for 10-12 months. One of the mimicry weed is being prevalent in the Nagauri (Paan) methi and hence economic value while the quality produce procurement can be mixed with this weed and deterioration in quality product. So the various challenges/constraints are exists in the production of Nagauri (Paan) methi. It has a special fragrance, aromatic and basically famous as Paan methi in the whole World. Nagauri (Paan) methi is majorly exporting in USA, Japan, Qatar, Tanzania, UAE, Nigeria, China, Australia and Nepal. Nagauri (Paan) methi has an average annual INR 550-600 


\section{Pawariya et al.}

crores export value. That's why the geographical indication is desirous by the farmers of this area. Most of the agricultural produce is being marketed through mandi APMC, e-NAM (online trading) and export. There are number of problems exist in the production and marketing of the produce. Farmers produces the various agricultural produce but while buying and selling take place through marketing channels which includes intermediaries, ahratiyas, mandi houses, traders and ultimately to consumer and henceforth big price spread.Lack of infrastructure like storage, transportation, quality control, packaging, price risk management, cool chains, market led extension, and conducive framework for promotion of contract farming are some of the other important constraints for competitive agricultural marketing system in the country (Gohain et al., 2018) hence, about 90 per cent of the marketable surplus was disposed off just after the harvest (Rajesh and Sundaresan, 2002). Moreover, due to lack of food processing and storage, the grower farmer is deprived of a good price for his produce during the peak marketing season while the consumer needlessly pays a higher price during lean season (Ramkishen, 2004). Nagauri (Paan) methi is one of the produce which is not listed in minimum support price and it doesn't have an appropriate market place. There is less number of traders present in the production area so the price gain to farmers is the main issue. This crop is not being buying and selling in mandis premises. Total 25 mandis are linked with e-NAM (National Agriculture Market) and rest of the 131 mandis is being linked with e-NAM but Nagauri (Paan) methi is not linked with this portal although it deals with the more than 90 products. A lion's share of the Nagauri (Paan) methi is being export but still market power is in the hands of few traders. Rajasthan has 28.70 lakh ton storage capacities and processing share is only $1.5 \%$ in the whole India (Rajasthan agriculture export policy, 2019). So there is various constraints prevails in the market area which need to rise for the promotion and elevation of farmers for economic and social development. About one among every four farmers complained that the charges deducted by the market functionaries were high (Kshirsagar, 2006). And hence the exploitation of the farmers is happening in the agricultural produce marketing. So there are various constraints for the marketing of Nagauri
(Paan) methi exists in the study area. To address the production and marketing constraints/problems and determining the helpful policy measures and further improvement, the present study was taken place.

\section{Material and Methods}

The present study was undertaken in the state of Rajasthan to study the marketing and production constraints farmers in the marketing of Nagauri (Paan) methi. A total of two districts were selected for the study namely Nagaur and some part of Jodhpur there only it is being grown $100 \%$ area of total Rajasthan. (Lal et al., 2014). For the present study total 150 farmers of 30 villages of both the district were selected randomly. The primary data for the study pertains to the period 2018-19. Furthermore, the sample farmers were categorized according to the operational landholding of the farmers. The five categories of the sample farmers were taken for the purpose of study as marginal ( $<1$ ha of operational holding), small (1-2 ha), semimedium (2-4 ha), medium (4-10 ha) and large farmers $(<10 \mathrm{ha})$ according to the area under cultivation of Nagauri (Paan) methi. From table 1 the sampled marginal farmers were $18.67 \%$ age, small farmers $26.67 \%$ age, semi medium 30.67 $\%$ ages, medium farmers $16 \%$ age and large farmers were $8 \%$ age.

Garrett's ranking technique is employed for ranking the preferences of respondents on different variables. This method helps to identify the most significant variable influencing the respondent (Dhanavandan, 2016). By this method the respondents are asked to rank their preference for all factors. The resultant outcomes of such rankings are converted to per cent position using the formula:

$$
\text { percent position }=\frac{100(R i j-0.5)}{N j}
$$

Where,

$\mathrm{Rij}=$ Rank given for the $\mathrm{i}^{\text {th }}$ variable by $\mathrm{j}^{\text {th }}$ respondents.

$\mathrm{Nj}=$ Number of variable ranked by $\mathrm{j}^{\text {th }}$ respondents.

From the Garrett's Table, the \% position calculated is converted into scores. Then for each factor, the scores of each individual are added and then total value of scores and mean values of score is calculated. The factors having highest mean value is considered to be the most important factor. 
Table 1. Category wise distribution of sample farmers according to of Nagauri (Paan) methi in Rajasthan.

\begin{tabular}{|l|l|}
\hline Category of farmers & Number of farmers \\
\hline Marginal & $28(18.67)$ \\
\hline Small & $40(26.67)$ \\
\hline Semi-medium & $46(30.67)$ \\
\hline Medium & $24(16.00)$ \\
\hline Large & $12(8.00)$ \\
\hline
\end{tabular}

Figure in parentheses are \%age of the total

\section{Results and Discussion}

The information provided by the stakeholders is presented in the tabular form according to operational holding of sampled farmers' category. 150 sampled farmers were responded the information regarding problems and constraints faced by them in the production and marketing of Nagauri (Paan) methi in Rajasthan. The Garrett's technique was used for the ranking of constraints in the marketing and production. After addressing the problems and constraints the appropriate suggestion were given in the section below. Table 2 shows the category wise problems faced by farmers in Rajasthan during marketing of their Nagauri (Paan) methi produce. Majority of the marginal farmers about $89 \%$ had the problem of lack of remunerative price of Nagauri (Paan) methi. Likewise about $90 \%$ of small farmers, $89 \%$ of semi medium farmers, $91 \%$ of medium and $91 \%$ of large farmers were faced the problem of not getting the remunerative prices of the crop. Followed by large farmers $(91 \%)$ and medium farmers $(95 \%)$ were facing the problem of lack of appropriate market center. About $91 \%$ large farmers and $87 \%$ of medium farmers were facing the problem of non-support of other societies which help to get the product well marketed. Table 2 revealed that other major constraints were lack of competitive firm available in market, transportation facilities, lack of grading, bulkiness of product, no minimum support price, lack of handling, lack of infrastructure, delay in payment etc.We have used the Garret's technique for the ranking of various problems/constraints faced by farmers in the marketing of Nagauri (Paan) methi. The major problems/constraints faced by farmers in the study area are lack of remunerative price, lack of appropriate market center, lack of grading, transportation, not list in MSP, lack of supporting societies, delay in payments, lack of infrastructure, bulkiness of the product and lack of suitable handling, which is shown in the table 2.It is revealed from table 3 that the most important problem faced by farmers' was unavailing the remunerative prices followed by lack of appropriate market centre. The farmers were not getting the appropriate price of the produce due to the unavailability of multiple markets and traders. The price spread was high in the Nagauri (Paan) methi and farmers were getting very minor share. As there is no defined market for the primary level farmers are forced to sell their crop at very less amount and it is second most perceived problem in the marketing of Nagauri (Paan) methi. Lack of competitive firms was the third constraint faced by the farmers (table 3). Due to that farmers were not able to get the fair prices and monopoly exists. The fourth constraint was lack of grading/ measure of quality parameters of leaves of the Nagauri (Paan) methi, which have the maximum share in the marketable produce. The same results were achieved by Sanga and Magimba (2016). Due to bulky nature of the produce the transportation constraint, was faced by majorly small farmers in the study area. Nagauri (Paan) methi not listed in minimum support price and hence the farmers are ultimately exploited in the bumper production, as none of the governmental price policy is announced for this produce. It is shown in table 3 that the seventh constraint of marketing of Nagauri (Paan) methi was lack of infrastructure and hence the farmers are not able to sell their produce and good prices and feeldemoralized. It has been observed from the response of mostly bigger farmers medium and large farmers that none of the cooperative society and any other supporting societies working in the area which results the ultimate exploitation of farmers in many ways of the Nagauri (Paan) methi. As there is none of the facilities by any union or government for the farmers of Nagauri (Paan) methi, farmers also had the handling issue of the produce. Government has introduced the Farmers Producer Organization concept and after having this much of potential of this crop farmers do not have any FPO of the Nagauri (Paan) methi in study area, this constraint is perceived by farmers in the marketing of the produce. The twelfth problem of marketing in was intermediaries' exploitation which has moderate rate to affect the farmers in the 
Pawariya et al.

Table 2. Category wise problems faced during marketing of Nagauri (Paan) methi in Rajasthan (Multiple responses)

\begin{tabular}{|l|l|l|l|l|l|}
\hline \multirow{2}{*}{ Problems/constraints } & \multicolumn{5}{|c|}{ Categories of Farmers (Frequency) } \\
\cline { 2 - 6 } & Marginal & Small & Semi Medium & Medium & Large \\
\hline Lack of remunerative prices & $25(89.29)$ & $36(90.00)$ & $41(89.13)$ & $22(91.67)$ & $11(91.67)$ \\
\hline Lack of appropriate market center & $23(82.14)$ & $35(87.50)$ & $39(84.78)$ & $23(95.83)$ & $11(91.67)$ \\
\hline Lack of competition & $22(78.57)$ & $32(80.00)$ & $40(86.96)$ & $20(83.33)$ & $10(83.33)$ \\
\hline Transportation & $13(46.43)$ & $25(62.50)$ & $27(58.70)$ & $15(62.50)$ & $5(41.67)$ \\
\hline Lack of grading & $17(60.71)$ & $22(55.00)$ & $38(82.61)$ & $18(75.00)$ & $6(50.00)$ \\
\hline Bulkiness of the product & $12(42.86)$ & $20(50.00)$ & $20(43.48)$ & $16(66.67)$ & $6(50.00)$ \\
\hline Lack of suitable handling & $12(42.86)$ & $15(37.50)$ & $29(63.04)$ & $17(70.83)$ & $7(58.33)$ \\
\hline Lack of infrastructure & $19(67.86)$ & $29(72.50)$ & $37(80.43)$ & $18(75.00)$ & $9(75.00)$ \\
\hline No MSP & $21(75.00)$ & $34(85.00)$ & $39(84.78)$ & $20(83.33)$ & $10(83.33)$ \\
\hline Lack of the supporting societies & $20(71.43)$ & $32(80.00)$ & $40(86.96)$ & $21(87.50)$ & $11(91.67)$ \\
\hline FPO not available & $18(64.29)$ & $30(75.00)$ & $30(65.22)$ & $15(62.50)$ & $6(50.00)$ \\
\hline Intermediaries exploitation & $14(50.00)$ & $27(67.50)$ & $25(54.35)$ & $16(66.67)$ & $3(25.00)$ \\
\hline Delay in payment & $10(35.71)$ & $25(62.50)$ & $26(56.52)$ & $12(50.00)$ & $8(66.67)$ \\
\hline Total number of farmers & $28(100.00)$ & $40(100.00)$ & $46(100.00)$ & $24(100.00)$ & $12(100.00)$ \\
\hline
\end{tabular}

Figure in parentheses are \%age of the total

Table 3. Ranking of problems and constraints faced by farmers in the marketing of Nagauri (Paan) methi in Rajasthan

\begin{tabular}{|l|l|l|}
\hline Problems/constraints & Garrett's Mean Score & Rank \\
\hline Lack of remunerative prices & 75.60 & I \\
\hline Lack of appropriate market center & 64.63 & II \\
\hline Lack of competition & 55.39 & III \\
\hline Lack of grading & 39.05 & IV \\
\hline Transportation & 35.13 & V \\
\hline None of the MSP & 34.72 & VI \\
\hline Lack of infrastructure & 34.35 & VII \\
\hline Lack of the supporting societies & 31.41 & VIII \\
\hline Lack of handling & 26.67 & IX \\
\hline Bulkiness of the product & 26.64 & X \\
\hline FPO not available & 21.78 & XI \\
\hline Intermediaries exploitation & 14.73 & XII \\
\hline Delay in payment & 8.64 & XIII \\
\hline
\end{tabular}

Table 4. Category wise problems faced in production of Nagauri (Paan) methi in Rajasthan (Multiple responses)

\begin{tabular}{|l|l|l|l|l|l|}
\hline \multirow{2}{*}{$\begin{array}{l}\text { Problems/ } \\
\text { constraints }\end{array}$} & \multicolumn{6}{l|}{ Categories of Farmers (Frequency) } \\
\cline { 2 - 6 } & Marginal & Small & Semi Medium & Medium & Large \\
\hline Drying of the leaves & $25(89.29)$ & $38(95.00)$ & $45(97.83)$ & $23(95.83)$ & $12(100.00)$ \\
\hline Irrigation & $23(82.14)$ & $37(92.50)$ & $41(89.13)$ & $20(83.33)$ & $10(83.33)$ \\
\hline $\begin{array}{l}\text { Less use of } \\
\text { technology }\end{array}$ & $22(78.57)$ & $36(90.00)$ & $44(95.65)$ & $22(91.67)$ & $11(91.67)$ \\
\hline $\begin{array}{l}\text { Seed Quality } \\
\text { availability }\end{array}$ & $21(75.00)$ & $35(87.50)$ & $42(91.30)$ & $21(87.50)$ & $11(91.67)$ \\
\hline Mimicry weed & $15(53.57)$ & $22(55.00)$ & $35(76.09)$ & $14(58.33)$ & $8(66.67)$ \\
\hline Drainage & $20(71.43)$ & $33(82.50)$ & $38(82.61)$ & $17(70.83)$ & $9(75.00)$ \\
\hline Total & $28(100.00)$ & $40(100.00)$ & $46(100.00)$ & $24(100.00)$ & $12(100.00)$ \\
\hline
\end{tabular}

Figure in parentheses are \%age of the total 
Table 5. Ranking of problems and constraints faced by farmers in the production of Nagauri (Paan) methi in Rajasthan

\begin{tabular}{|l|l|l|}
\hline Problems/constraints & Garrett's Mean Score & Rank \\
\hline Drying of the leaves & 73.41 & I \\
\hline Irrigation & 55.02 & II \\
\hline Less use of technology & 48.60 & III \\
\hline Seed Quality availability & 39.87 & IV \\
\hline Mimicry weed & 23.19 & V \\
\hline Drainage & 17.94 & VI \\
\hline
\end{tabular}

marketing of Nagauri (Paan) methi. Out of these thirteen constraints delaying payment was least observed problem by farmers (table 3 ). As the most of the farmers was dealing with cash payment. Results were on the lines of Gohain et al. (2018) and Islam et al. (2019). It has revealed from table 4 analysis of problems/ constraints faced by the farmers in the production of Nagauri (Paan) methi in Rajasthan that Drying of the leaves was most affecting factor of the production in all categories of farmers in the study area. Almost all the sampled large farmers, $98 \%$ of semi medium, $96 \%$ of medium farmers, $95 \%$ of small farmers and $89 \%$ of marginal farmers were having the problem of drying the leaves of the Nagauri (Paan) methi in Rajasthan. Irrigation was second important constraint was mostly perceived by small farmers. Less use of technology in the production of the Nagauri (Paan) methi was third constraint followed by quality seeds availability and mimicry weeds. Drainage was least affecting problems in the production of Nagauri (Paan) methi by the growers (table 4). By the Garrett's technique it has been mentioned in table 5, the mean score of Drying of leaves problem faced by farmer was maximum and it is 73.41 and henceforth it is ranked first in constraints received by farmers in the study area in the all categories of farmers because of the less use of Good Agricultural Practices (GAP), none of the innovation in the drying of leaves and weather and natural calamities. Irrigation was the second most ranked constraint in the study area because this crop need a large quantity of water about 12-15 irrigations and so the irrigation constraint occur by small farmers due to non-availability of the water resources and due of practice of water buying (GWM) (Pawariya et al., 2017).As this crop has a great economic values and commercialization is world famous of this crop, unfortunately there none of the technology intervention happened. So far only two varieties are there of this crop and farmers are using the local seeds for the crop. So this is fourth major constraint faced by the farmers. The major producible component of this crop is leaves and one mimicry weed is there in the production of the crop. Farmers does not checked that variety and hence this is again fifth major constraint in the production of Nagauri (Paan) methi (table 5). Drainage is the issue of this crop too because of this issue seeds cannot be producedand ranked sixth by the Garrett's technique. So this problem was identified in the study by the computation of problems faced by farmers in the production of Nagauri (Paan) methi in Rajasthan. Outcome was on the same line on Nidhi et al. (2017).

\section{Conclusion}

To identify problems and constraints of farmers in the marketing and production in Nagauri (Paan) methi with the use of Garrett's ranking technique revealed that in case of Nagauri (Paan) methi the most important constraint identified by the stakeholders in the study area was the lack of attaining remunerative price which was perceived by $90 \%$ of the farmers and ranked I with garrets mean score 75.60 followed by certain unavailability of defined market center ranked II, lack of competitive firms and inappropriate quality measurement (ranked IV). The least perceived constraint by the farmers in the marketing of Nagauri (Paan) methi was delayed payments which Garret's mean score were 8.64 ranked XIII. The major constraint in production of Nagauri (Paan) methi was drying of leaves which were faced by 95 per cent of the farmers and least affected problem was drainage issue ranked II. To check the marketing constraints the establishment of market yard and remunerative price should be given to producers and technology intervention should be introduced in the production of Nagauri (Paan) 


\section{Pawariya et al.}

methi like good agricultural practices, drying should include into minimum support price crops tunnels can be uses. Furthermore, Nagauri (Paan) for the minimization of the constraints. methi should give the geographical indication and

\section{References}

Dhanavandan, S. 2016. Application of Garret Ranking Technique: Practical Approach. International Journal of Library and Information Studies. 6(3): 135-140

Gohain, N. and Singh, S. 2018. An Analysis of Problems and Constraints Faced by Farmers in Marketing of Agricultural Produce in Punjab. Economic Affairs, 63(3): 671-678.

Islam, R., Ali S., Alam M., Shahriar S. A. and Moin J. 2019. Farmer's Constraints for Vegetables Marketing in Bangladesh. Asian Journal of Advances in Agricultural Research, 11(2): 1-9.

Kshirsagar, K. G. 2006. Availing Marketing Infrastructure for Horticultural Crops: Emerging Perspectives and Future Policies. Indian Journal of Agricultural Marketing, 20(2): 69-80.

Lal, G., Saran, P. L., Devi, G., Deepak and Rishi R. 2014. Production Technology of Fenugreek (Trigonella foenumgraecum L.). Book chapter in advances in vegetable agronomy. Chapter 39: 244-252.
Nidhi, N. J., Ardeshna, B. N. and Shilpa V. C. 2017. Problems of Agricultural Marketing in India. Redears shelf. 13(5)57.

Pawariya, V., Sharma, R. C. and Sharma, B. K. 2017. Factors Influencing Groundwater Markets in Rajasthan. Agricultural Research Journal, 54(4): 572-577.

Rajesh, R. and Sundaresan, R. 2002. Marketing Decision by Farmers and their Operational Constraints. Encyclopaedia of Agricultural Marketing, 3: 269-82.

Ramkishen, Y. 2004. New Perspectives in Rural and Agricultural marketing. Jaico Publications, Mumbai, India.

Sanga, A. and Mgimba, C. 2016. An Analysis of Constraints that Affect Smallholder Farmers in the Marketing of Tomatoes in Mbeya Urban and Peri-Urban, Tanzania. Imperial Journal of Interdisciplinary Research (IJIR), 2(3): 603-611. 